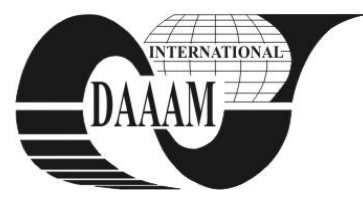

Annals of DAAAM for 2011 \& Proceedings of the 22nd International DAAAM Symposium, Volume 22, No. 1, ISSN 1726-9679 ISBN 978-3-901509-83-4, Editor B. Katalinic, Published by DAAAM International, Vienna, Austria, EU, 2011 Make Harmony between Technology and Nature, and Your Mind will Fly Free as a Bird

\title{
NAIL ELEMENT AS A JOINING FEATURE BETWEEN HIGH-STRENGTH TUBE AND SLEEVE
}

\author{
URBANEK, M[iroslav]; HRONEK, P[avel] \& MASEK, B[ohuslav]
}

\begin{abstract}
Widespread expansion of modern high-strength materials requires new types of joints, which do not impair the vast potential materials to be joined. The alternative type of joint proposed in this study is intended for joining a highstrength tube with a sleeve from structural steel by means of socalled nail element. The nail element is a special disk-shaped element with a central hole, transmitting the load from the sleeve to a tubeby means of a blade. The load transmission is based on the nail element biting into the tube

Key words: joint, nail, forming, high-strength, tube
\end{abstract}

\section{INTRODUCTION}

Permanent joints between high-strength low-alloyed steels are difficult to produce by conventional methods, such as welding. Heat introduced into high-strength steel by welding typically degrades the properties of the parent metal. This is why the key task of engineering designers is to develop new alternative joint types for modern high strength low-alloyed steels. The above described alternative joint is designed for joining a high-strength $50 \mathrm{~mm}$ diameter tube with a structural steel sleeve. The key load-carrying part of the structure is the nail element.The nail element has been designed as a special load-carrying disk-shaped element with a circular hole. The load is transmitted by the blade of the working edge of the opening. The more effective the biting action of the nail element, the higher is the load-carrying capacity of the joint.

The requirements for material properties of the nail element comprise high yield strength and ultimate tensile strength throughout its volume and a high hardness of the working edge.

One of possible joint concepts uses two nail elements transmitting the load in both directions (Fig. 1). The nail element is fitted on the tube and held between the flanges by screws. The clamping action of the two flanges makes the working edge of the nail element bite into the tube (Fig. 3). Due to confined installation space, the screws run through the holes in the nail element (Mašek et al., 2010).

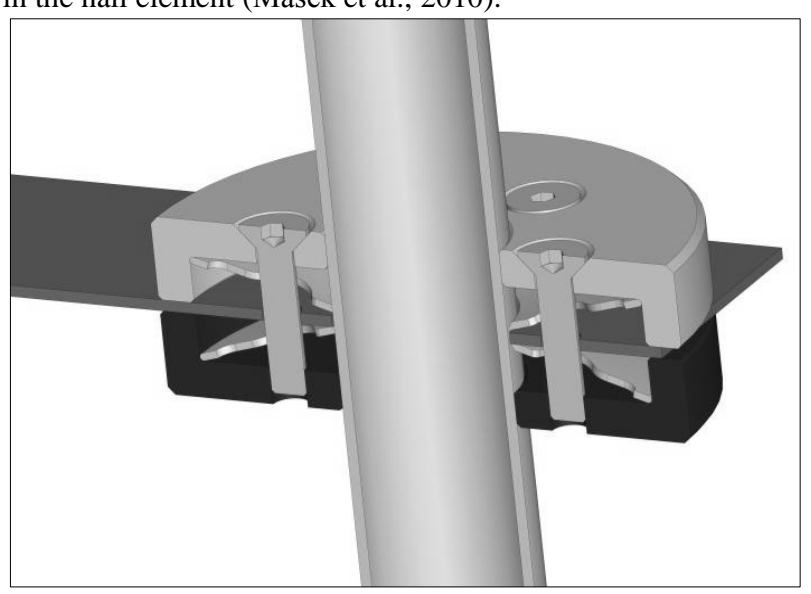

Fig. 1. Example joint with two nail elements

\section{ENGINEERING DESIGN OF THE JOINT}

The design of the basic shape of the nail element was inspired by intuition. The final shape was obtained by stepwise modifications with the aid of FEM simulation (Fig. 2). Numerical simulations were used at three levels of the problem.

The first simulation level concerned the stiffness and strength of the nail element. The purpose of the task was to find a suitable shape of the element. The design variants were verified using numerical models with rather low numbers of shell elements. The model only comprised the nail element itself. The remaining components were defined through the boundary conditions.

Once the shape of the nail element was verified in terms of stiffness and strength, the joint was analysed as an assembly consisting of the nail element, the tube and two flanges (see Fig. 3). The purpose of simulation at this level was to describe the behaviour of the nail element in interaction with other structural parts.

The third level of numerical simulation was aimed at the nail element biting into the high-strength tube. Several variants of the blade were simulated. The final simulation concepts contained over one million solid elements and non-linear features, such as the contact problem and non-linear material defined by its stress-strain curve and work hardening effects. The simulation was computed in two steps. The first step was the simulation of the assembly and clamping action of the joint, i.e. the nail element biting into the tube. The second step was the simulation of increasing load acting on the flange surface.

Results of the simulation were used for making an actual joint which was then subjected to an axial overload test. (Nový et al., 2007)

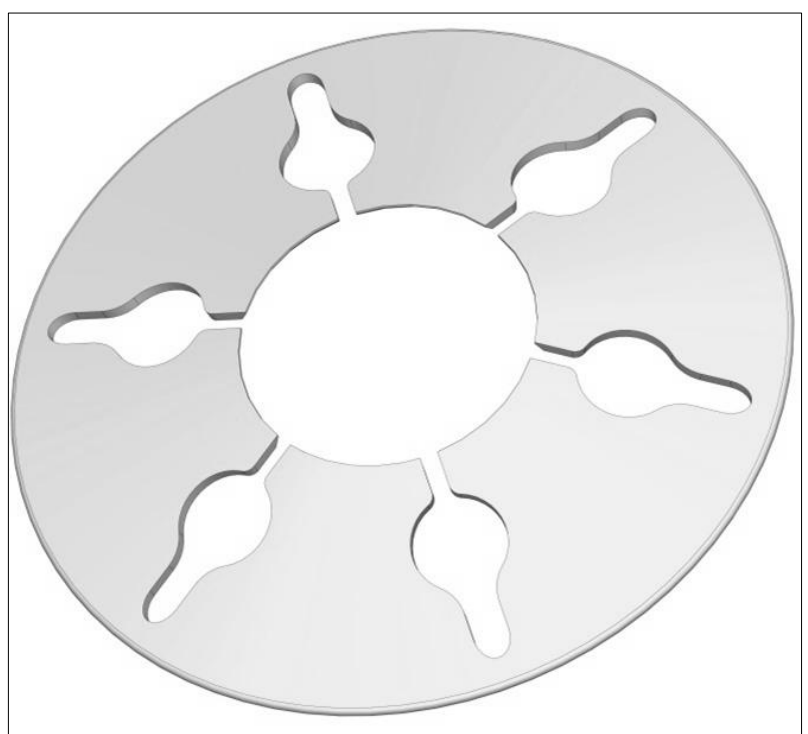

Fig. 2. FEM simulation-based design of the nail element 


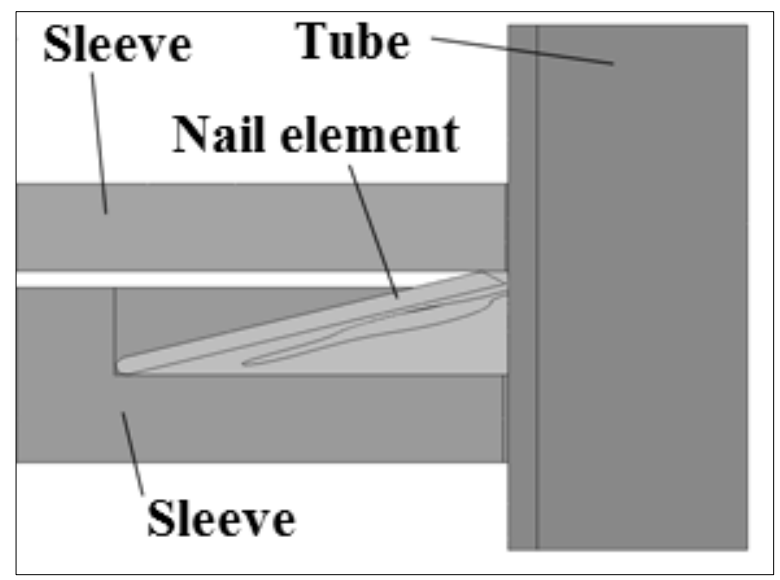

Fig. 3. Section through the joint before assembly

\section{NAIL ELEMENT PRODUCTION}

The crucial part of the joint is the nail element. It was manufactured from a $2 \mathrm{~mm}$ steel sheet used for making springs. The blank was made by laser cutting. Its conical shape was obtained by quenching between dies, which led to the hardness of up to $49 \mathrm{HRC}$. The equivalent strength obtained by conversion of the hardness value was about 1,640 Mpa (Mašek et al., 2009).

\section{LOAD-CARRYING CAPACITY OF THE JOINT}

The load-carrying capacity of joints with a single nail element was tested on specimens under quasi-static conditions at room temperature. The specimens consisted of a highstrength tube, two flanges and a nail element (Fig. 3). The tube was fixed at one end. A linearly increasing force was applied on the entire surface of the sleeve. The boundary conditions were identical to those used in the simulation. (Urbánek et al., 2010)

Two specimens with different nail element hardnesses of 44 and 49 HRC were tested. The load-carrying capacity of the joint was shown to depend on the hardness of the nail element working edge.

The response of the nail element changed from initial elastic deflection to plastic deformation (Fig. 4). After the loadcarrying capacity was exceeded (approx. $15 \mathrm{kN}$ ), the sleeve began to slide along the tube. The load-carrying capacity test record (Fig. 4) shows the behaviour of the joint under load depending on the loading force and crosshead displacement.

Both curves suggest a positive feature of the joint safety: the overload does not lead to catastrophic failure, once the loadcarrying capacity is exceeded, in contrast to welded joints. . (Nový et al., 2007)

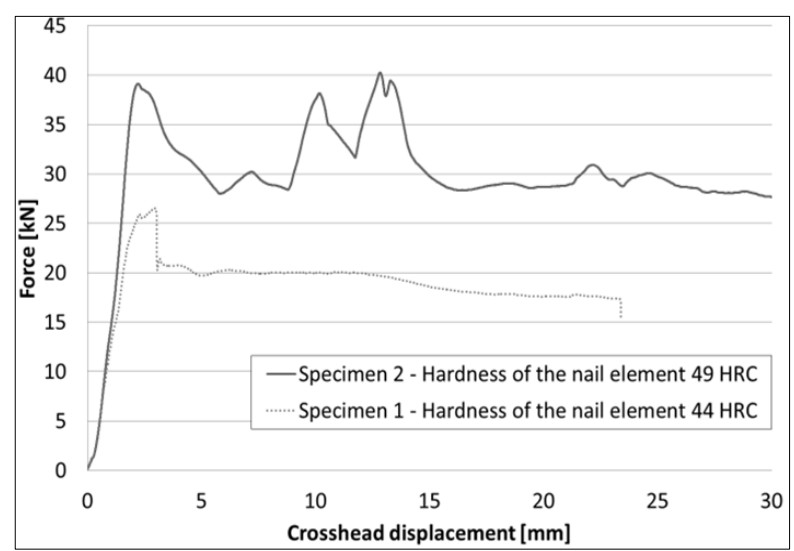

Fig. 4. Behaviour of the joint under load vs. hardness of the nail element

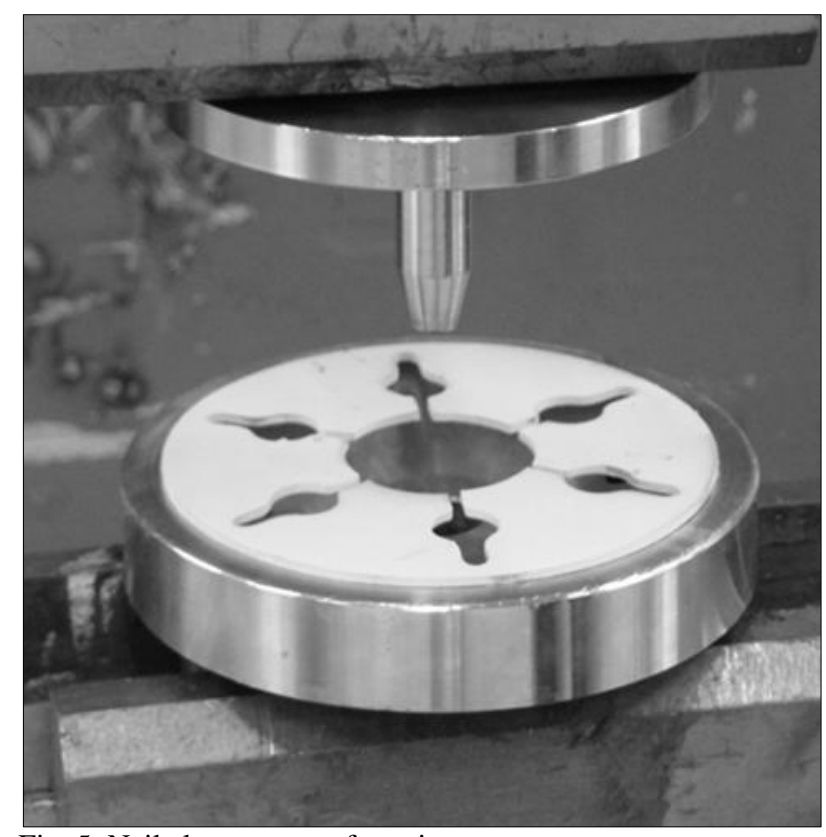

Fig. 5. Nail element manufacturing

\section{CONCLUSION}

The purpose of the study was to design an alternative type of a joint between a high-strength tube and a structural steel sleeve using a nail element. The shape of the joint was designed with the aid of numerical simulation. The proposed configuration was manufactured and its load-carrying capacity was tested using nail elements with two different hardnesses. The joint's load-carrying capacity was found to depend on the hardness of the nail element. In the specimen with hardness of $49 \mathrm{HRC}$ it was about $20 \mathrm{kN}$, whereas the $44 \mathrm{HRC}$ specimen sustained $15 \mathrm{kN}$ load. A very simple manufacturing process and the simplicity of use make this joint type a very promising concept, thanks to the fact that it does not fail suddenly under overload. The joint supports the loading force along a very long trajectory and therefore absorbs a large amount of deformation energy.

\section{ACKNOWLEDGEMENTS}

This paper includes results obtained within the project $1 \mathrm{M}$ Research Centre of Forming Technology.

\section{REFERENCES}

Duchek, M.; Nový, Z. \& Urbánek, M. (2010) High-strenght girders for the construction industry,In DAAAM 2010, Zadar, Croatia, p. 1177-1178, ISSN 1726-9679

Mašek, B.; Urbánek, M.; Nesvadba, P. \& Hronek, P. (2010). Alternative Explosion-Formed Joint of High-Strength Tube and Sleeve,In DAAAM 2010, Zadar, Croatia, p. 1181-1182, ISSN 1726-9679

Nový, Z. \& Urbánek, M.(2007) Lisovaní nerozebíratelné spoje rámových konstrukcí, In Forming 2007, Podbanské, Slovensko, ISBN 978-80-227-2702-0

Nový, Z. \& Urbánek, M. (2009). The alternative jointing method, ICIT\&MPT 2009, 7th International Conference on Idustial Tools and Material Processing Technologie, Ljubjana, Slovenia, p.101-106 ISBN, 2009, 961-6692-01-4

Urbánek, M.; Hronek, P; Nesvadba, P. \& Mašek, Bohuslav. Alternativní spoj vysokopevné trubky s objímkou vytvořený výbuchem, In COMAT 2010, Plzeň, p.71-72, ISBN 978-80-254-8683-2 